\title{
BMJ Open The perspective of European researchers of national occupational safety and health institutes for contributing to a European research agenda: a modified Delphi study
}

\author{
Diana Gagliardi, ${ }^{1}$ Bruna M Rondinone, ${ }^{1}$ Marco Mirabile, ${ }^{1}$ Giuliana Buresti, ${ }^{1}$ \\ Peter Ellwood, ${ }^{2}$ Michel Hery, ${ }^{3}$ Peter Paszkiewicz, ${ }^{4}$ Antonio Valenti, ${ }^{1}$ Sergio lavicoli ${ }^{1}$
}

To cite: Gagliardi D, Rondinone BM, Mirabile M, et al. The perspective of European researchers of national occupational safety and health institutes for contributing to a European research agenda: a modified Delphi study. BMJ Open 2017;7:e015336. doi:10.1136/ bmjopen-2016-015336

- Prepublication history and additional materials are available. To view these files, please visit the journal online (http://dx.doi.org/10.1136/ bmjopen-2016-015336)

Received 1 December 2016 Revised 8 March 2017 Accepted 13 April 2017

\section{(a) CrossMark}

${ }^{1}$ Department of Occupational and Environmental Medicine, National Institute for the Insurance against Work Accidents (INAIL), Monteporzio Catone, Italy

${ }^{2}$ Foresight Centre, Health and Safety Executive, Buxton, UK ${ }^{3}$ Foresight Unit, National Institute for Research and Safety (INRS),

Paris, France

${ }^{4}$ Institute for Occupational Safety and Health of the German Social Accident Insurance (IFA), Sankt Augustin, Germany

Correspondence to

Dr Diana Gagliardi;

d.gagliardi@inail.it

\section{ABSTRACT}

Objectives This study, developed within the frame of the Partnership for European Research on Occupational Safety and Health joint research activities and based on the frame designed by the 2013 European Agency for Safety and Health at Work (EU-OSHA) study, is the first example of using the points of view of European occupational safety and health (OSH) researchers. The objective is to identify priorities for $\mathrm{OSH}$ research that may contribute to the achievement of present and future sustainable growth objectives set by the European strategies.

Methods The study was carried out using a modified Delphi method with a two-round survey. Each round involved a panel of about 110 researchers representing the network member institutes was selected according to specific criteria, including the ownership of research expertise in at least one of the four macroareas identified by the reference report developed by EU-OSHA in 2013. Results The study identified some innovative research topics (for example, 'Emerging technological devices' and ' $\mathrm{OSH}$ consequences of markets integration') and research priorities (ie, crowdsourcing, e-work, zero-hours contracts) that are not reflected in previous studies of this nature. The absence of any reference to violence and harassment at work among the researchers' proposals is a major difference from previous similar studies, while topics related to gender issues and electromagnetic fields show a lower importance.

Conclusions The innovative design of a research priorities identification process, which takes advantage of a large, representative and qualified panel of European researchers allowed the definition of a number of research priorities able to support the inclusion of innovative OSH research issues in the scope of the next European research agenda.

\section{INTRODUCTION}

Demographic changes, globalisation and technological innovation, are continuously reshaping the world of work, with a direct impact on workers' health and safety. ${ }^{12} \mathrm{New}$ occupational risk factors are emerging owing to the introduction of new technologies,

\section{Strengths and limitations of this study}

- This is the first occupational safety and health (OSH) research priorities setting study able to provide a reliable expression of the perspective of the European OSH Research Community together with an analysis of differences between European geographical areas thanks to the involvement of a wide, transdisciplinary and transnational panel of European highly qualified OSH researchers from 12 pre-eminent European national institutes.

- The study takes advantage of an innovative methodological path that integrates the top-down and bottom-up approaches to steer the researchers' involvement in each step of the priority setting process towards the provision of feasible research priorities responding to four predetermined $\mathrm{OSH}$ research challenges identified by the European Agency for Safety and Health at Work (EU-OSHA) on the basis of the strategic objectives set at a European level.

- A limitation of the study was represented by the possibility of researchers to promote their own research activities as priorities, which is inconsistent with the need of going beyond the boundaries of sectoral research and being highly interdisciplinary.

- Another limitation of the study was the composition of the researchers' panel, reflecting only the $\mathrm{OSH}$ competencies related to the macrothemes shaped by the four challenges, devoid of the skills specific of correlated research fields that could be relevant for a broader assessment of the strategic and synergic impact of the priorities on the European research framework.

substances and work processes, changes in the structure of the workforce and the labour market, and new forms of employment and work organisation'. ${ }^{3}$ Furthermore, changes in social or public perceptions and the development of scientific knowledge allow long-standing issues to be considered afresh 
or identified as emerging risks. ${ }^{4}$ Despite the good results already achieved by the European occupational health and safety $(\mathrm{OSH})$ approach in terms of outcomes or indicators (such as work injuries prevention), these changes require further efforts to allow the OSH system to be able to effectively improve prevention of work-related illness as well as accidents. ${ }^{5}$ OSH research, thus, needs to maintain a pivotal role in the development of policies for the improvement of workers' health and safety, allowing the OSH system to identify and tackle emerging issues in a timely way. ${ }^{6}$

Actually, different European and national research agendas have already given relevant space to many of the issues highlighted by this study, and this should ensure the capacity for a timely, efficient and effective use of available resources to address the challenges presented by the changing world of work.

With this aim, in 2013 the European Agency for Safety and Health at Work (EU-OSHA) developed a study to connect OSH research objectives with both the Europe 2020 strategy and the Horizon 2020 programme and their key objectives of 'smart, sustainable and inclusive growth' and 'excellent science-competitive industries-better society'. ${ }^{7-9}$

The study identified four major challenges, which OSH research should use to support the pursuit of these objectives, as well as the research priorities to tackle these challenges.

This study is the most recent in a series of national and European level studies started in the early 1990s to identify research priorities able to fill the OSH knowledge gaps caused by the changes in the world of work. ${ }^{10}$

A critical review of such studies, though, showed that at a European level a methodical and structured elicitation of the researchers' view aimed at the identification of research gaps and a fine-tuning of well-defined research priorities has always been missing, even if it would be complementary and add significant value. In the majority of cases, researchers' involvement in the development of these studies was not the primary focus and in any case downstream of previous elaborations developed by selected teams of OSH experts.

Also, the findings of the 2013 EU-OSHA study, despite consultation with a larger panel of OSH experts (including researchers, in addition to stakeholders and other $\mathrm{OSH}$ professionals), were strongly rooted on a preliminary and in-depth desk analysis carried out by a restricted team of experts.

The only European level study which saw a large and effective involvement of researchers (alongside other OSH experts) was based on a set of four Delphi surveys conducted by the EU-OSHA Risk Observatory between 2004 and $2006 .{ }^{411-13}$ Nevertheless, this study focused more on new and emerging risk factors than on real priorities for research, and its final output was the identification of general OSH issues to be addressed. ${ }^{14}$

However, there are a number of well-documented national studies aimed at supporting the drafting of
OSH research strategies which, beside the participation of different experts (OSH professionals, OSH services, policy-makers, social parties, etc), provide a full and direct involvement of the researchers' community in the priorities setting process. Such experiences, mostly based on Delphi surveying methods, took place in the USA, Malaysia, UK, the Netherlands and Italy. Some of these studies (Italy and the Netherlands) also provided a distinct representation of researchers' point of view. ${ }^{15-20}$

The importance of surveying the research community is based on the premise that researchers, as main actors of research activities, are in a strong position to provide a real-time and realistic picture of the state-of-the-art and to define what is currently missing to properly tackle the upcoming challenges, as long as they are able to look beyond their current research activity. Furthermore, a wide, substantive and full involvement of researchers in the process of identification of research priorities can assess their feasibility, according to the current scientific evidence and their consistent integration into existing research activities. Therefore, a clear and accurate representation of the expectations of the research community representing a relevant number of European national research institutes can provide a useful starting point for a strategy planning process aiming to produce an $\mathrm{OSH}$ research agenda. ${ }^{21} 22$

For this reason, in 2014 the Partnership for European Research on Occupational Safety and Health (PEROSH), a network of 12 OSH research institutes across Europe, approved the joint research project 'Futures. Foresight and priority setting in OSH', led by the Italian National Institute for the Insurance against Work Accidents with the collaboration of the Institute for Occupational Safety and Health of the German Social Accident Insurance (Germany), the National Institute for Research and Safety (France) and Health and Safety Executive's Health and Safety Laboratory (UK).

Starting from the challenges identified in the 2013 EU-OSHA study, ${ }^{7}$ the 'Futures' project aimed at providing an updated identification of research needs and at prioritising them by the level of consensus among the researchers working in the network member institutes. To this end, it took advantage of the large number of multidisciplinary researchers working in the member institutes and of the good geographical coverage of the network itself. Unlike previous European level studies focusing on foresight activities and using the Delphi method, this is the first one to include only researchers in the Delphi panel and to focus exclusively on the identification of research topics and priorities, which the OSH research community considers fundamental for an effective development and improvement of the OSH system management.

This study integrates the agenda made by decision makers with the view of researchers, by enriching the bottom-up process where researchers represent the primary source for the identification of future research priorities and not only the final step for the assessment of proposals developed by a small number of experts. 


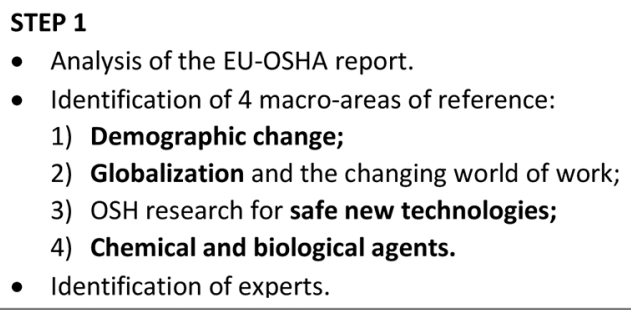

- Analysis of the EU-OSHA report.

- Identification of 4 macro-areas of reference:

1) Demographic change;

2) Globalization and the changing world of work;

3) OSH research for safe new technologies;

4) Chemical and biological agents.

- Identification of experts.

\section{STEP 2 - DELPHI FIRST ROUND}

$\mathrm{N}_{\text {sent }}=126, \mathrm{~N}_{\text {received }}=94, \mathrm{RR}=74.6 \%$

- Open-ended questionnaires, one for each macro-area.

- Each participant was requested to list 3 to 5 well-focused research issues on which there is a need for further research.

- Collection of research proposals and elaboration of research priorities.

- Definition of 16 Research Topics and 77 Research Priorities.

\section{7}

\section{STEP 3 - DELPHI SECOND ROUND}

$N_{\text {invited }}=112, N_{\text {received }}=75, R R=67.0 \%$

- One questionnaire to all experts.

- Scale of importance 0-5 plus "I don't know" option.

- Analysis of data: Mean Values, Standard Deviation, percentages and geographical analysis.

Figure 1 The modified Delphi process adopted in the study.

The purpose of this study is to provide a timely contribution to the development of European OSH research agendas to allow their effective alignment with the needs arising from the world of OSH research. It offers a picture of the researchers' points of view, which may represent the baseline of a strategic planning process, which should subsequently include a wider community of stakeholders, such as social partners and decision makers. The study also needs to react to the increasing reductions in funds for OSH research, as priority-setting processes are critical in aligning research funding with evidence needs as well as in supporting an efficient allocation of limited resources available for research.

\section{METHODS}

The study was based on a two-round modified Delphi survey, which involved a panel of researchers from all PEROSH institutes. The project's leader and co-coordinators (Coordination Group) developed the methodological path and shared it with the PEROSH Steering Committee. The method used is illustrated in figure 1 .

The Delphi technique is a well-suited and accepted method for consensus building by using a series of questionnaires to collect data from a panel of selected subjects concerning a specific topic. ${ }^{23} 24$ Also, it is one of the most widely used techniques for priority setting in OSH. ${ }^{10}{ }^{15-20}$

The main features of the Delphi method (anonymity, iteration, controlled feedback, statistical 'group response') make it more suitable than others to obtain the opinion of a panel of experts on a predetermined topic, especially when dealing with geographically dispersed participants ${ }^{25}$ or when the information available on a given topic are incomplete or poor. ${ }^{26}$

In this study, a modified Delphi method was adopted, by using four different questionnaires (one for each of the four macroareas included in the EU-OSHA report) with a well detailed and focused (though open-ended) question on a specific matter. The use of a modified Delphi study is considered an appropriate option when information concerning the project is already partially available. ${ }^{27} 28$

\section{Step 1-desk analysis}

The first step consisted of an in-depth analysis of the EU-OSHA report 'Priorities for occupational safety and health research in Europe: 2013-2020', aimed at updating OSH research priorities identified in 2005 and taking into account the latest developments in scientific knowledge, the changes in the world of work and the impact of recent trends on OSH. The report also considered the priorities and key objectives set in the Europe 2020 strategy and the Horizon 2020 programme. ${ }^{7-9} 29$

The EU-OSHA report includes four macroareas, which were taken as landmarks for this study:

1. Demographic change-sustainable work for healthier and longer working lives.

2. Globalisation and the changing world of work- $\mathrm{OSH}$ research contribution to sustainable and inclusive growth.

3. OSH research for safe new technologies as a prerequisite for sustainable growth.

4. Research into new or increasing occupational exposures to chemical and biological agents for the benefit of a smart and sustainable economy.

All the PEROSH institutes contributed to the study by providing contact persons. Their task was to identify 5-20 expert researchers from each institute to be included in the panel, according to the following selection criteria: specific research experience (at national and possibly also international levels) in one or more of the four macroareas and a present or planned direct involvement in research activities related to the relevant macroarea. Contact persons were requested to ensure anonymity among participants to reduce the impact of dominant individuals.

\section{Step 2. Delphi questionnaire-first round}

The first round took place between March and April 2015. For each macroarea, a specific open-ended electronic questionnaire was sent to a subpanel of researchers, selected by their area of expertise (online supplementary file 1). Some researchers were indicated as experts for more than one macroarea.

Considering the total number of experts identified, participants were asked to list, within their field of expertise, three to five well-focused research issues on which there is a need for further research. 


\section{Step 3. Delphi questionnaire-second round}

Starting from the research proposals returned at the end of the first round and using keywords and recurrences of concepts to group together similar issues and to reduce the total number of research proposals and to avoid repetition and overlapping, the coordination group elaborated a structured questionnaire divided into 16 'research topics' (RT), each one containing a list of consistent 'research priorities' (RP). The identification of the RT was based on the main structure of the EU-OSHA report, reflecting the general content of each macroarea. There were only few disagreements that were discussed among the study team in a face-to-face meeting.

Before the second round, a preliminary pilot test was performed to assess accessibility of the platform and comprehensibility of the research proposals as well as to estimate the duration of the interviews. The pilot study involved 16 participants identified within the coordination group institutes. Feedback and comments were taken into account in designing for the final version of the survey.

For the second round of consultation, which took place between February and March 2016, the questionnaire was sent to the entire sample of researchers involved in the project, irrespective of their area of expertise and of their active participation in the first round.

In this round, researchers were asked to rate the level of importance of each RP and RT considering whether it is addressing a real OSH research gap and the impact that OSH research might have in terms of the breadth of the workers' population affected and the severity of avoidable damages to health. The rating system was based on a scale of importance, from 0 (=not at all important) to 5 (=extremely important). The system provided also the 'I don't know' option, allowing those researchers who felt not to have enough expertise on a specific item to abstain (online supplementary file 2 ).

The questionnaire was circulated in English through the dedicated web-based platform SurveyMonkey; the researchers involved received an electronic invitation by email, directly generated by the system. Two reminder emails were sent, the second one informing of a 1 week extension of the deadline to increase the response rate.

To reduce response biases, the system provided a randomisation of the RP in each page and a reversed order of the pages for $50 \%$ of the sample. The page with the list of RT was excluded from any randomisation process.

Ratings given in the second round were analysed by calculating mean values (MV) and SD for each RP and each RT. Percentages were also calculated considering those attributing no importance at all $(0)$ and grouping together those attributing a low level of importance (little-1 or slight importance-2), and those attributing a medium-high level of importance (from moderate-3 to extreme-5) to each RP and RT.

There are many criteria to establish the achievement of consensus. Among them, SD values and percentages have been used as 'consensus indicators'. In detail, the research team agreed that a good level of consensus was achieved when at least $50.0 \%$ of the responders attributed a medium to high level of importance to the item and the $\mathrm{SD}$ value was lower than 1.50 . As all the topics and all the priorities, except for two, were consistent with this criteria, it was decided not to perform any further round.

It should also be considered that there are no firm rules to establish when consensus is achieved, but usually, the stricter the criteria, the more difficult it is to obtain consensus. ${ }^{30}$ In addition, available scientific literature shows that repeated rounds may lead the respondents to fatigue and increased attrition ${ }^{31}$; this is why the number of rounds can be limited to two without affecting the quality of the results. ${ }^{32} 33$

Keeping in mind the European countries represented within the network, a geographical classification of participants, based on a modified UN classification, was performed, grouping together Denmark, Finland, Norway and UK for Northern Europe; Austria, France, Germany, the Netherlands and Poland for Central Europe (Western and Eastern Europe were gathered together as Central Europe to assure a homogeneous representativeness of researchers in the subsamples) and Italy and Spain for Southern Europe. MV for each RP and RT were calculated with respect to the geographical distribution; statistically significant differences were evaluated by applying the Kruskal-Wallis test; post hoc tests were used to assess which MV were significantly different from the others. The post hoc tests used were Bonferroni or Tamhane, depending on whether variances were homogeneous or non-homogeneous according to the Levene test. Significance was set at $\mathrm{p}<0.05$. Data were analysed using SPSS Statistics V.21.

\section{RESULTS}

In the first round of Delphi, 126 questionnaires were forwarded to 110 researchers; some researchers received more than one questionnaire as they were quoted as experts in more than one macroarea. Ninety-four questionnaires were returned, providing 354 research proposals, quite equally distributed among the four macroareas. Accounting for a few changes in the original list of participants, 112 researchers were invited to participate in the second round, 75 of whom completed the online questionnaire. Response rates were $74.6 \%$ in the first round and $67.0 \%$ in the second round (table 1).

Table 2 shows the geographical distribution of respondents. All the PEROSH member institutes contributed actively to the entire survey. In the first round, $41.5 \%$ of responses were from Central Europe, $33.0 \%$ from Northern Europe and 25.5\% from Southern Europe. In the second round, the figures were substantially the same for Central Europe (41.3\%), while they decreased to $26.7 \%$ for Northern Europe and increased to $32.0 \%$ for Southern Europe.

The research proposals underwent a process of classification based on the identification of keywords 
Table 1 Response rate for rounds 1 and 2

\begin{tabular}{|c|c|c|c|}
\hline \multirow[b]{2}{*}{ Macroarea } & \multicolumn{2}{|l|}{ Round 1} & \multirow{2}{*}{$\begin{array}{l}\text { Round } 2 \\
\text { Response } \\
\text { rate, \% }\end{array}$} \\
\hline & $\begin{array}{l}\text { Response } \\
\text { rate, \% }\end{array}$ & $\begin{array}{l}\text { Research } \\
\text { proposals }\end{array}$ & \\
\hline 1. Demographic change & 80.0 & 104 & \\
\hline 2. Globalisation & 76.9 & 72 & \\
\hline 3. New technologies & 65.6 & 82 & \\
\hline $\begin{array}{l}\text { 4. Chemical and } \\
\text { biological agents }\end{array}$ & 75.8 & 96 & \\
\hline Total & 74.6 & 354 & 67.0 \\
\hline
\end{tabular}

and recurrence of similar concepts. Sixteen RTs were identified and traced to the macroarea of reference according the structure of the EU-OSHA report. Each RT contained a variable number of priorities, totalling 67 RPs. Another $10 \mathrm{RPs}$, related to more transversal research issues and difficult to trace back to a specific RT were included in a special section named 'Miscellaneous'.

Table 3 shows the MV and SD calculated for each RT both in the general sample and by geographical distribution of respondents. Percentage response frequencies are also shown. According to the analysis performed, the top five RTs were as follows:

1. Older workers, with 3.90 ,

2. Nanomaterials with 3.89 ,

3. Emerging technological devices with 3.87,

4. Chemical agents with 3.83,

5. Working conditions, working organisation and job content with 3.81 .

The subsequent topics, down to the 14 th place, obtained MV higher than 3.00. Only the last two RTs reached MV lower than 3.00-OSH consequences of markets integration with 2.85 and electromagnetic fields with 2.59.

The comparison by geographical areas showed significant differences in the MV only for three RTs:

1. Women at work and gender aspects, with a significantly higher score in Southern Europe (3.74) compared with Northern Europe (2.74) (Tamhane,

Table 2 Geographical distribution of respondents for rounds 1 and 2

\begin{tabular}{llclc}
\hline & \multicolumn{2}{l}{ Round 1 $(\mathbf{n = 9 4 )}$} & \multicolumn{2}{l}{ Round 2 $(\mathbf{n = 7 5 )}$} \\
\cline { 2 - 5 } Country & Frequency & Per cent & Frequency & Per cent \\
\hline $\begin{array}{l}\text { Northern } \\
\text { Europe }\end{array}$ & 31 & 33.0 & 20 & 26.7 \\
$\begin{array}{l}\text { Central } \\
\text { Europe }\end{array}$ & 39 & 41.5 & 31 & 41.3 \\
$\begin{array}{l}\text { Southern } \\
\text { Europe }\end{array}$ & 24 & 25.5 & 24 & 32.0 \\
\begin{tabular}{l} 
Total \\
\hline
\end{tabular} & 94 & 100.0 & 75 & 100.0 \\
\hline
\end{tabular}

$\mathrm{p}=0.031$ ) and Central Europe (2.93) (Tamhane, $\mathrm{p}=0.026)$;

2. Nanomaterials, where the MV for Southern Europe (4.36) is significantly higher than for Central Europe (3.69) (Tamhane, $\mathrm{p}=0.006$ );

3. Electromagnetic fields, with an MV in Northern Europe (1.82) significantly lower than in Central Europe (2.92) (Bonferroni, $\mathrm{p}=0.012$ ) and Southern Europe (2.83) (Bonferroni, $\mathrm{p}=0.042$ ).

Furthermore, the analysis of frequencies pointed out that $90 \%-95 \%$ of the sample evaluated moderately to extremely important the RTs in the higher ranking positions, vouching for a strong consensus on such issues.

Table 4 displays the top five RPs in each macroarea according to MV obtained (see online supplementary table for the extended titles of research priorities and the complete list of descriptive statics).

In the macroarea related to demographic change (12 RPs classified into 5 RTs), all the RPs obtained an MV between 3.22 and 3.88. Among these, six had an MV $>3.50$ (two in disabled workers, three in older workers and one in migrant workers). The SD was between 0.92 and 1.21. The percentage frequencies for the mediumhigh level of importance (from $3=$ moderately important to $5=$ extremely important) ranged from a minimum of $75.4 \%$ ( 1 in women at work) to a maximum of $92.6 \%$ (1 in disabled workers). The percentage of 'I don't know' in this macroarea was between $5 \%$ and $10 \%$.

In the macroarea related to globalisation and the changing world of work (19 RPs classified into 4 RTs), MV varied between a minimum of 2.75 and a maximum of 3.81. Only the priority related to use and abuse of substances improving working performance had an MV below 3.00. Ten RPs had an MV between 3.10 and 3.48 (one in employment patterns and practices, one in $\mathrm{OSH}$ consequences of markets integration, three in reorganisation processes and five in working conditions). Eight RPs obtained an MV between 3.52 and 3.81 (three in employment patterns and practices, one in OSH consequences of markets integration, one in reorganisation processes and three in working conditions). The SD was between 0.86 and 1.20. The percentage frequencies for the mediumhigh level of importance (except for use and abuse of substances improving working performance with 58.2\%) ranged from $72.6 \%$ to $92.9 \%$; in 12 out of 19 RPs, this percentage was higher than $80.6 \%$. Few RPs received over $10 \%$ of 'I don't know'; in one case, this percentage was 26. $7 \%$.

In the macroarea related to safe new technologies (21 RPs classified into 5 RTs), there were only three priorities with an MV lower than 3.00, all included in the electromagnetic fields topic. Eight RPs had an MV varying between 3.00 and 3.50 (four in emerging technological devices, three in information and communication technology (ICT) and one in nanomaterials). Ten RPs had MV between 3.51 and 4.00 (six in nanomaterials, two in ICT and two in green jobs). Similarly to the other 




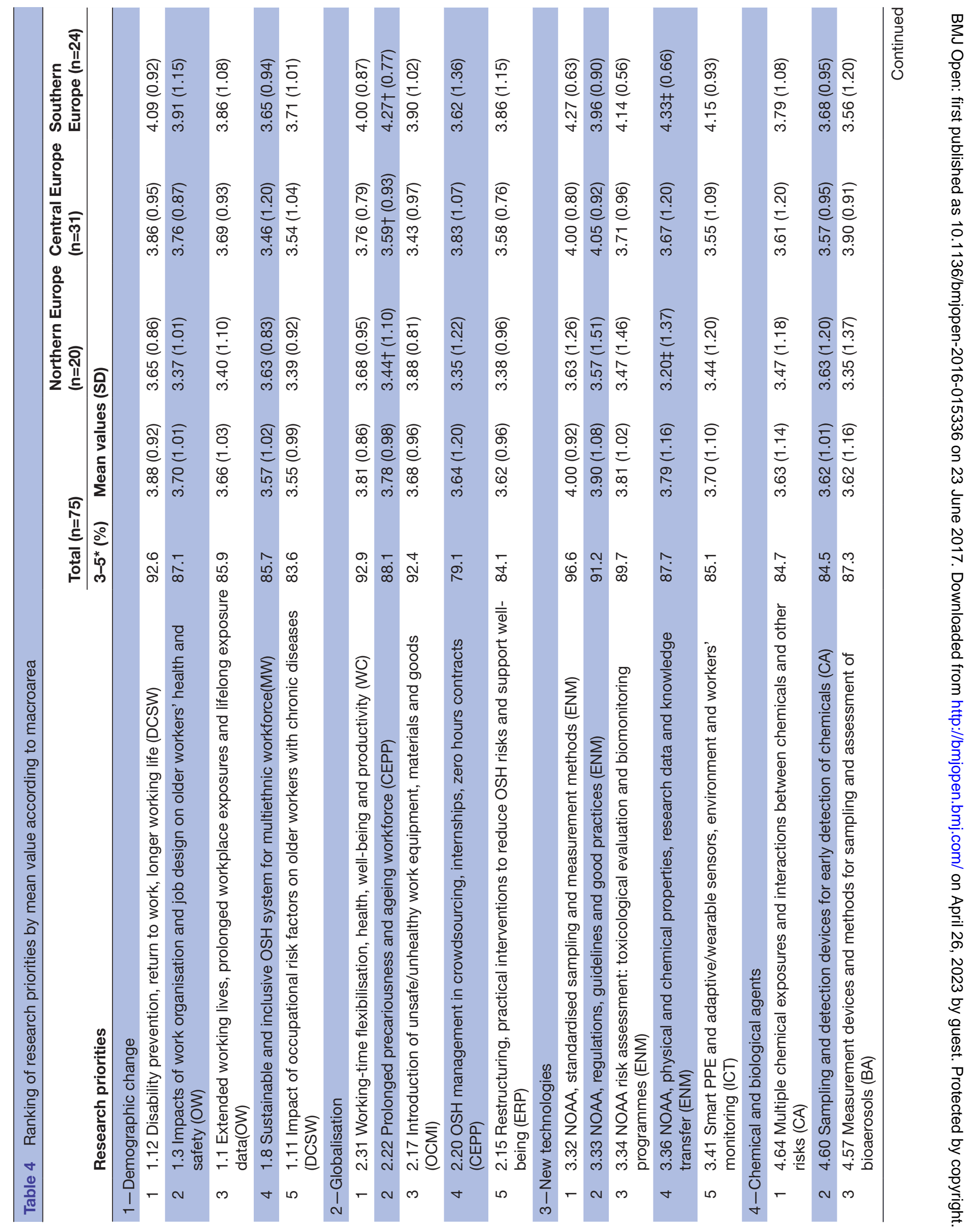




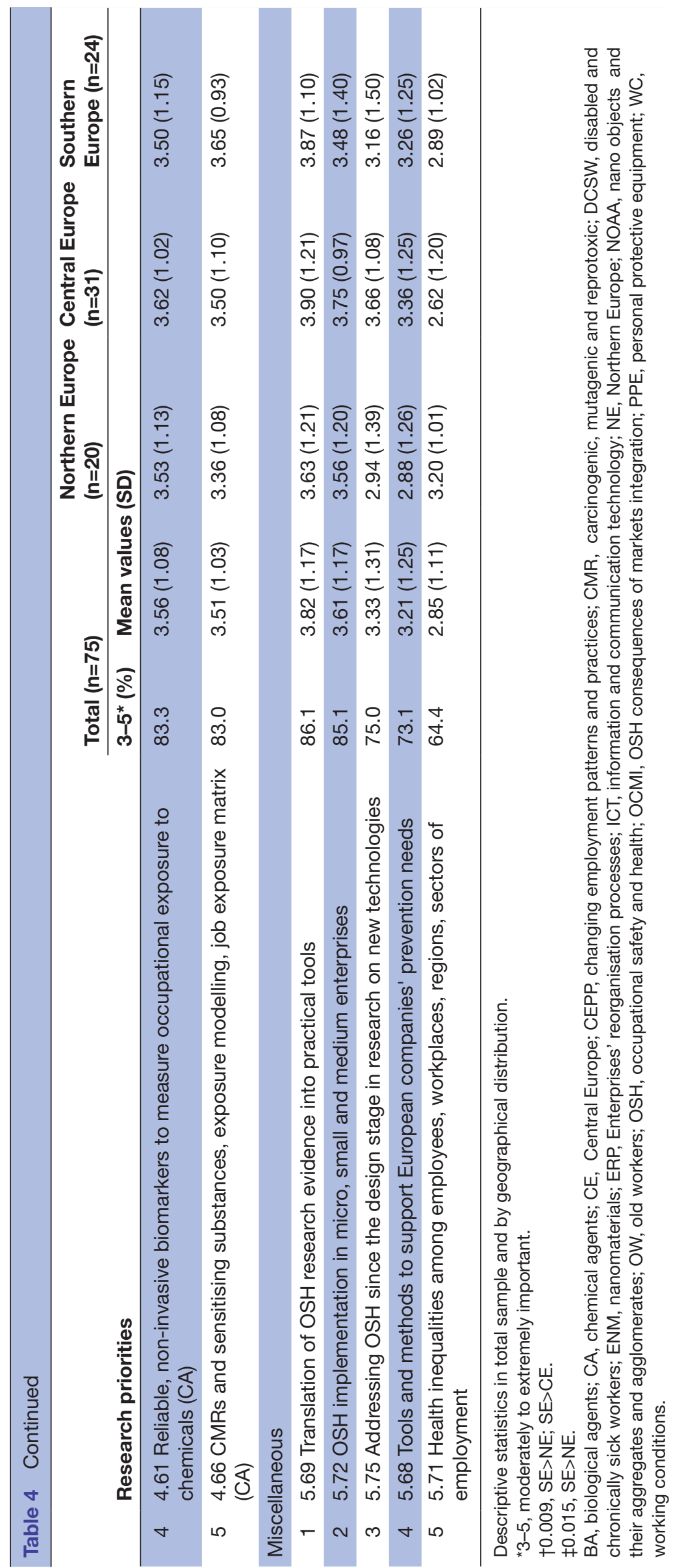

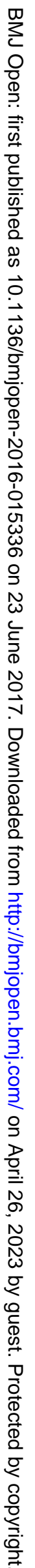


macroareas, the SD is between 0.98 and 1.47. As regards the percentage frequencies for the medium-high level of importance, it was below $80.0 \%$ in $5 \mathrm{RPs}$, while 13 reached values between $82.8 \%$ and $96.6 \%$. For all the RPs in this macroarea, the percentage of 'I don't know' is higher than $10 \%$; in 14 cases, it ranged between $16.0 \%$ and $29.3 \%$.

In the macroarea related to chemical and biological agents (15 RPs classified into 2 RTs), MV varied between 2.84 and 3.63. Five RPs had an MV higher than 3.50 (four in chemical agents and one in biological agents); two RPs had an MV below 3.00 (one in chemical agents and one in biological agents). For the remaining eight RPs (three in chemical agents and five in biological agents), MV was between 3.00 and 3.50. The SD was between 0.97 and 1.37. The percentage frequencies for the medium-high level of importance ranged for all RPs between $61.8 \%$ and $87.3 \%$, with nine RPs with a percentage higher than $80.0 \%$. In this macroarea, the percentage of 'I don't know' was between $20 \%$ and $38.7 \%$.

\section{DISCUSSION}

The high level of participation in both rounds, with a high number of relevant research proposals submitted in the first, confirms the interest of the research community in being directly involved in the definition of research agendas and planning activities.

As regards the results, it is useful to note that 14 out of the 16 RTs coming from the first round of Delphi questionnaire obtained an MV between 3.14 and 3.90, showing a positive evaluation in terms of importance. In particular, the first 12 RTs were rated $\geq 3$ by at least $80 \%$ of the sample.

Ageing of the workforce and return to work look to be the core issues in the area of demographic change, underlining the importance of answering the needs of prolonging working life in a healthy and productive way. However, topics still included in the area of demographic change, which had a consolidated and relevant space within recent $\mathrm{OSH}$ agendas, such as vulnerable workers in general, migrant workers and gender issues seem to attract a lower interest in terms of OSH research.

In the area of technological innovation, the most relevant topic is that related to nanotechnologies. Nevertheless, the analysis by geographical distribution shows a specific relationship: in fact, this topic has the highest MV in Southern Europe, while its importance is significantly lower in the other geographical areas.

It is interesting to note that in the macroarea related to technological innovation, emerging technological devices appears, for the first time with this study, as an autonomous OSH research topic. As a matter of fact, the general topic obtained a higher rating than the specific priorities traced under this heading. This might be due to the perception that this kind of devices can have relevant long-term impacts in terms of innovation and sustainable growth, while the specific research priorities actually identified are still linked to small and very specific projects, only precursors to wider future developments. It must be also noted that the level of importance attributed to this topic overtakes that of two other topics showing a much steadier link between health and safety and technological innovation, such as ICT and green jobs.

The lower importance assigned to ICT as a discrete topic might be due to the inclusion of the risks related to ICT as such into some other topics, like work organisation, job content and ageing. However, green jobs still look not to have a full relevance within OSH issues. In fact, the priorities included in this topic highlight the need to develop a better knowledge and to define the effective relevance of the risks for workers' health and safety related to these technologies.

Enterprises' reorganisation processes and OSH consequences of markets integration are the two RTs that received the lowest rating among those included in the macroarea of globalisation. For the first, this might be due to the specific focus of research on actions to improve risk management and reduce risk exposure during these processes, rather than studying the impact of exposures, whose effects are already well known. For the second, notwithstanding the low MV obtained by the RT, the two RPs included received a much higher evaluation: the reason for this might be due to an unclear wording of the RT, while the more detailed definition of the priorities supported a better comprehension of the related OSH issues.

Among the RTs with the lowest rating, women at work and electromagnetic fields are also included. The low ranking of women at work is in line with previous findings, which highlighted a relevant attention to the issue in terms of OSH implementation but not as an autonomous research topic. ${ }^{29} 3435$ However, the analysis by geographical distribution suggests some new food for thought, worthy of further study. Unlike other regions, Southern Europe ranked both the RT and the related RPs among the highest in order of importance.

As regards electromagnetic fields, there is a clear contrast with previous studies. In fact, in the studies carried out by EU-OSHA to identify OSH research priorities, there was a strong emphasis on the need to explore the effects of the new applications of this technology. ${ }^{4}$ On the contrary, this study shows a significant reduction in interest for this issue, with an MV lower than three in all the geographical regions and even lower than two in Northern Europe.

Among the 77 RPs included in the second round of the Delphi survey, 65 were rated with an MV higher than 3 (moderately important), recognising a medium-high level of importance to the RP. This level of importance was assigned by at least $80 \%$ of the respondents in 44 RPs.

Some very new issues appeared among the top priorities. Particular importance has been attached to OSH management in new forms of employment (eg, crowdsourcing, internships, zero hours contracts); OSH 
impacts of innovation and new ways of working (ie, telework, e-work, boundary less work); health and safety in human-computer interaction and the introduction of unsafe and unhealthy work equipment following the reduction of barriers to the free movement of goods.

Finally, high importance was attributed to two transversal priorities related to the translation of research results into practical and effective tools and to the support for $\mathrm{OSH}$ implementation in micro, small and medium enterprises.

\section{Strengths and limitations}

The methodological approach used in this study develops previous experiences in an innovative way, by defining a path of full involvement of the research community in each step of the priority setting process, from the identification of priorities to the assessment of their relevance and their ranking by level of importance.

The involvement of a European network of $\mathrm{OSH}$ research institutions has ensured not only a good representation of competencies and resources available across the network member institutes but also a wide geographical coverage that made it possible to analyse the different level of perception and awareness of the several issues in different European regions.

However, the attitude of researchers to promote their own research activities as priorities represents a limitation of the study, particularly for the development of future research agendas, which goes beyond the boundaries of sectoral research and needs to be highly interdisciplinary to meet the objectives of innovative and sustainable growth set by the European research strategy.

These limitations have been mitigated, at least partially, by the identification of well-defined fields of interest through the reference to the four macroareas of the EU-OSHA report. ${ }^{7}$ In addition, the decision to invite the overall sample to assess the level of importance of the entire set of priorities, not only of those included in their macroarea of expertise, allowed reduction of the importance of the single respondent's evaluations and consequently decreased the impact of such a bias.

\section{Comparison with previous studies}

This study ratifies the central role of some RTs whose relevance was already widely acknowledged by the literature. However, topics related to gender issues and electromagnetic fields, although still receiving high attention at policy level, show a lower demand for research.

In previous studies, gender issues were included in different areas of interest, both autonomously and related to exposure to particular risks (ie, endocrine disruptors). In this study, instead, gender issues obtained lower MV than other topics related to vulnerable workers, which made them slip out of the top five priorities in the macroarea (see online supplementary table for effective ranking of the topic and related priorities).
As regards electromagnetic fields, acknowledging that this topic has had a great relevance in the past both at political level and within the research community, they obtained the lowest MV (2.59).

Differently from previous studies, including the 2013 EU-OSHA report, the present one showed the absence of any reference to the themes of violence and harassment at work. Even if these issues are still relevant or becoming important in some countries in the world, it must be acknowledged that they have never been mentioned in this study, not even among the over 350 research proposals collected at the end of the first round.

The study identifies some innovative RTs that are not reflected in previous studies, such as emerging technological devices and OSH consequences of markets integration. Some new elements are also highlighted among RPs, such as new forms of work delivery (eg, crowdsourcing, e-work, zero-hour contracts), which were only hinted in the 2013 EU-OSHA study.

\section{CONCLUSIONS}

This study allowed the identification and assessment of the relevance of a well-organised and fine-tuned set of RPs suitable for drawing up a proper agenda for further development of OSH research. This has been achieved through a process entirely shared with a large, geographically representative and qualified panel of European OSH researchers.

Therefore, it offers an effective representation of the OSH research community views on the needs for future research developments, able to contributing to the achievement of the innovation and sustainable growth objectives set by the European strategies.

Those priorities receiving a positive evaluation with a high level of consensus may represent the backbone of a reliable set of OSH research issues in the settlement of the next European Research Agendas.

Correction notice This paper has been amended since it was published Online First. Owing to a scripting error, some of the publisher names in the references were replaced with 'BMJ Publishing Group'. This only affected the full text version, not the PDF. We have since corrected theseerrors and the correct publishers have been inserted into the references.

Contributors SI promoted the project and the work. DG, BMR and SI each made substantial contributions to the conception and design of the study protocol. DG, $\mathrm{BMR}, \mathrm{MM}, \mathrm{PE}, \mathrm{MH}$ and PP contributed to the collection and elaboration of data. BMR and GB designed and performed the data analysis. BMR, MM and AV wrote the manuscript. DG, PE, MH, PP and SI provided critical inputs regarding the discussion and conclusions of the manuscript. DG and SI revised the final version of the manuscript. SI approved the final version of the manuscript to be published.

\section{Competing interests None declared.}

Patient consent This study was not conducted on patients and does not contain personal medical information.

Provenance and peer review Not commissioned; externally peer reviewed.

Data sharing statement All available data have been published within the paper and the annex.

Open Access This is an Open Access article distributed in accordance with the Creative Commons Attribution Non Commercial (CC BY-NC 4.0) license, which 
permits others to distribute, remix, adapt, build upon this work non-commercially, and license their derivative works on different terms, provided the original work is properly cited and the use is non-commercial. See: http://creativecommons.org/ licenses/by-nc/4.0/

(C) Article author(s) (or their employer(s) unless otherwise stated in the text of the article) 2017. All rights reserved. No commercial use is permitted unless otherwise expressly granted.

\section{REFERENCES}

1. Iavicoli S. The new EU occupational safety and health strategic framework 2014-2020: objectives and challenges. Occup Med 2016;66:180-2.

2. European Agency for Safety and Health at Work (EU-OSHA). Scoping study for a foresight on new and emerging occupational safety and health (OSH) risks and challenges. Luxembourg: Publications Office of the European Union, 2014. https://osha.europa.eu/en/tools-andpublications/publications/reports/scoping-study-for-a-foresight-onnew-and-emerging-osh-risks-and-challenges/view.

3. European Agency for Safety and Health at Work (EU-OSHA). Green jobs and occupational safety and health: foresight on new and emerging risks associated with new technologies by 2020. Luxembourg: Publications Office of the European Union, 2013. https://osha.europa.eu/en/tools-and-publications/publications/ reports/green-jobs-foresight-new-emerging-risks-technologies.

4. European Agency for Safety and Health at Work (EU-OSHA). Expert forecast on emerging physical risks related to occupational safety and health. Luxembourg: Publications Office of the European Union, 2005. https://osha.europa.eu/en/tools-and-publications/publications/ reports/7807118

5. European Commission. Evaluation of the European Strategy 20072012 on health and safety at work. Brussels, 31.5.2013. SWD(2013) 202 final: Commission staff working document.. http://ec.europa.eu/ social/BlobServlet?docld=10410\&langld=en. (access Oct 2016).

6. Rantanen J. Research challenges arising from changes in worklife. Scand J Work Environ Health 1999;25:473-83.

7. European Agency for Safety and Health at Work (EU-OSHA). Priorities for occupational safety and health research in Europe: 2013-2020. Luxembourg: Publications Office of the European Union, 2013. https://osha.europa.eu/en/tools-and-publications/publications/ reports/priorities-for-occupational-safety-and-health-research-ineurope-2013-2020/view/

8. European Commission. Europe 2020 - a strategy for smart, sustainable and inclusive growth, Communication from the Commission. Brussels, 3.3.2010. COM(2010) 2020 final. http://eurlex.europa.eu/LexUriServ/LexUriServ.do?uri=COM:2010:2020:FIN: EN:PDF. (accessed Oct 2016).

9. European Commission. Horizon 2020 - the framework programme for research and innovation, Communication from the Commission to the European Parliament, the Council, the European Economic and Social Committee and the Committee of the Regions. Brussels, 30.11.2011. COM(2011) 808 final. http:// http://eur-lex.europa. eu/LexUriServ/LexUriServ.do?uri=COM:2011:0808:FIN:en:PDF. (accessed Oct 2016).

10. lavicoli S, Rondinone B, Marinaccio A, et al. Research priorities in occupational safety and health: a review. Ind Health 2006;44:169-78.

11. European Agency for Safety and Health at Work (EU-OSHA). Expert forecast on emerging biological risks related to Occupational Safety and Health. Luxembourg: Publications Office of the European Union;2007 https://osha.europa.eu/en/tools-and-publications/ publications/reports/7606488.

12. European Agency for Safety and Health at Work (EU-OSHA). Expert forecast on emerging psychosocial risks related to occupational safety and health. 2007. Luxembourg: Publications Office of the European Union. https://osha.europa.eu/en/tools-and-publications/ publications/reports/7807118.

13. European Agency for Safety and Health at Work (EU-OSHA). Expert forecast on emerging chemical risks related to occupational safety and health.Luxembourg Publications Office of the European Union;2009 https://osha.europa.eu/en/tools-and-publications/ publications/reports/TE3008390ENC_chemical_risks.

14. Reinert D, Flaspöler E, Hauke A, et al. Identification of emerging occupational safety and health risks. Safety Science Monitor 2007;3:1-17.

15. Harrington JM. Research priorities in occupational medicine: a survey of United Kingdom medical opinion by the Delphi technique. Occup Environ Med 1994;51:289-94.

16. Harrington JM, Calvert IA. Research priorities in occupational medicine: a survey of United Kingdom personnel managers. Occup Environ Med 1996;53:642-4.

17. Rosenstock L, Olenec C, Wagner GR. The National Occupational Research Agenda: a model of broad stakeholder input into priority setting. Am J Public Health 1998;88:353-6.

18. van der Beek AJ, Frings-Dresen $\mathrm{MH}$, van Dijk FJ, et al. Priorities in occupational health research: a Delphi study in the Netherlands. Occup Environ Med 1997;54:504-10.

19. Sadhra S, Beach JR, Aw TC, Tc A, et al. Occupational health research priorities in Malaysia: a Delphi study. Occup Environ Med 2001;58:426-31.

20. lavicoli S, Marinaccio A, Vonesch N, et al. Research priorities in occupational health in Italy. Occup Environ Med 2001;58:325-9.

21. Ranson MK, Bennett SC. Priority setting and health policy and systems research. Health Res Policy Syst 2009;7:27.

22. Viergever RF, Olifson S, Ghaffar A, et al. Checklist for health research priority setting: nine common themes of good practice. Health Res Policy Syst 2010;8:36.

23. Dalkey N, Helmer O. An experimental application of the DELPHI Method to the use of experts. Manage Sci 1963;9:458-67.

24. Linstone H, Turoff M. The Delphi Method: Techniques and applications: Addison Wesley Publishing, 1975.

25. Jairath $\mathrm{N}$, Weinstein J. The Delphi methodology (Part one): A useful administrative approach. Can J Nurs Adm 1994;7:29-40.

26. Hsu CC, Sandford BA. The Delphi technique: making sense of consensus. Pract Assess Res Eval 2007;12:1-8.

27. Kerlinger FN. Foundations of behavioral research. New York: Holt, Rinehart, and Winston, Inc, 1973.

28. Hsu CC, Sandford BA. Minimizing non-response in the Delphi process: how to respond to non-response. Pract Assess Res Eval 2007;12:62-78.

29. European Agency for Safety and Health at Work (EU-OSHA). Priorities for occupational safety and health research in the EU25. 2005: Publications Office of the European Union. https://osha. europa.eu/en/tools-and-publications/publications/reports/6805648.

30. Fink A, Kosecoff J, Chassin M, et al. Consensus methods: characteristics and guidelines for use. Am J Public Health 1984;74:979-83.

31. Walker AM, Selfe J. The delphi method: a useful tool for the allied health researcher . British Journal of Therapy and Rehabilitation 1996;3:677-81.

32. Ramos D, Arezes P, Afonso P. Application of the Delphi Method for the inclusion of externalities in occupational safety and health analysis. Dyna 2016;83:14-20.

33. McKenna HP. The essential elements of a practitioners' nursing model: a survey of psychiatric nurse managers. J Adv Nurs 1994;19:870-7.

34. European Agency for Safety and Health at Work (EU-OSHA). New risks and trends in the safety and health of women at work. 2013. Luxembourg: Publications Office of the European Union. https:// osha.europa.eu/en/tools-and-publications/publications/reports/newrisks-and-trends-in-the-safety-and-health-of-women-at-work.

35. European Commission. EU Strategic Framework on Health and Safety at Work 2014-2020, communication from the Commission to the European Parliament, the Council, the European Economic and Social Committee and the Committee of the Regions. Brussels, 6.6.2014. COM(2014) 332 final. http://eur-lex.europa.eu/legalcontent/EN/TXT/PDF/?uri=CELEX:52014DC0332\&from=en. (access Oct 2016). 